\title{
Bowel Arteriovenous Malformation: An Unusual Cause of Lower Gastrointestinal Bleeding in a Child
}

\author{
Krishna Kumar Govindarajan Ramesh Ananthakrishnan Sajini Jacob \\ Department of Pediatric Surgery, Jawaharlal Institute of Postgraduate Medical Education and Research, \\ Pondicherry, India; Department of Radiodiagnosis, Jawaharlal Institute of Postgraduate Medical Education \\ and Research, Pondicherry, India; Department of Pathology, Jawaharlal Institute of \\ Postgraduate Medical Education and Research, Pondicherry, India
}

\section{Keywords}

Bleeding per rectum - Lower gastrointestinal bleeding . Obscure gastrointestinal bleeding $\cdot$ Bowel arteriovenous malformation

\section{Abstract}

In a child, lower gastrointestinal tract bleeding can be attributed to different etiologies. Unusually, the presence of bowel arteriovenous malformations can lead to multiple bouts of painless bright red bleeding per rectum, which develop into severe anemia. The article focuses on the diagnosis and management of bowel arteriovenous malformation in a child.

( 2020 Sociedade Portuguesa de Gastrenterologia Published by S. Karger AG, Basel

\section{Malformação arteriovenosa intestinal: uma causa} rara de hemorragia digestiva baixa numa criança

\section{Palavras Chave}

Sangramento por reto - Sangramento gastrointestinal inferior - Sangramento gastrointestinal obscuro .

Malformação arteriovenosa do intestino

\section{Resumo}

A hemorragia digestiva baixa nas crianças pode ter diversas etiologias. Invulgarmente, a presença de malformações arteriovenosas no intestino pode levar a múltiplos episódios hemorrágicos, com desenvolvimento de anemia grave. Este artigo aborda o diagnóstico e tratamento de uma malformação arteriovenosa intestinal numa criança.

(c) 2020 Sociedade Portuguesa de Gastrenterologia Publicado por S. Karger AG, Basel

\section{Introduction}

Pediatric lower gastrointestinal bleeding (LGIB) in the emergency setting is rare, being observed in $<1 \%$ of children attending the emergency department [1]. When the source of the hemorrhage is beyond the ligament of Treitz, the typical presentation is bleeding per rectum. The blood passed out is bright red when the transit time is $<14 \mathrm{~h}$, beyond which breakdown of hemoglobin leads to melena [2].

The presentation of bouts of bright red rectal bleeding with accompanying anemia in a child can be an alarming symptom to the parents. The paper discusses the presentation and management of an interesting case of bowel arteriovenous malformation (AVM). 


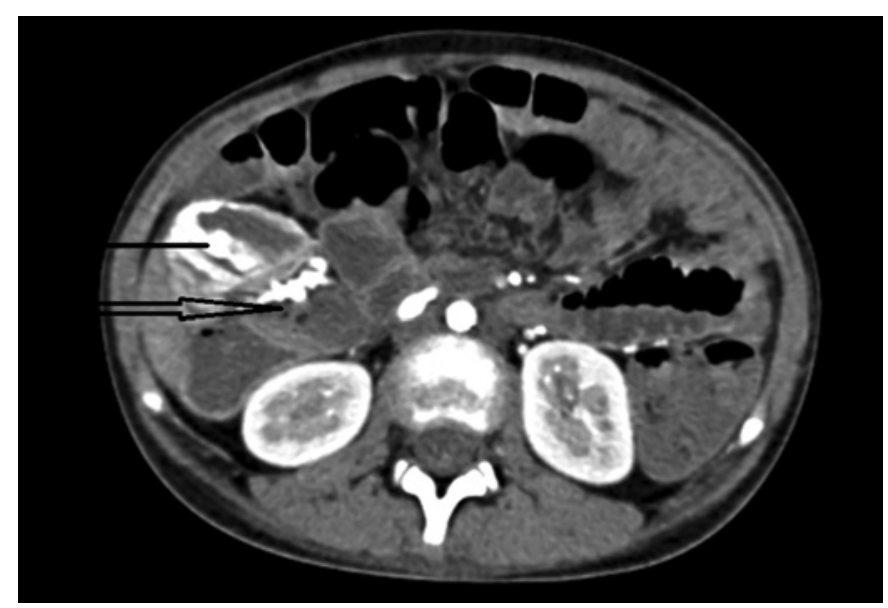

Fig. 1. Contrast-enhanced CT of the abdomen showing enhancement of the bowel wall (thin arrow) and leash of vessels (thick arrow).

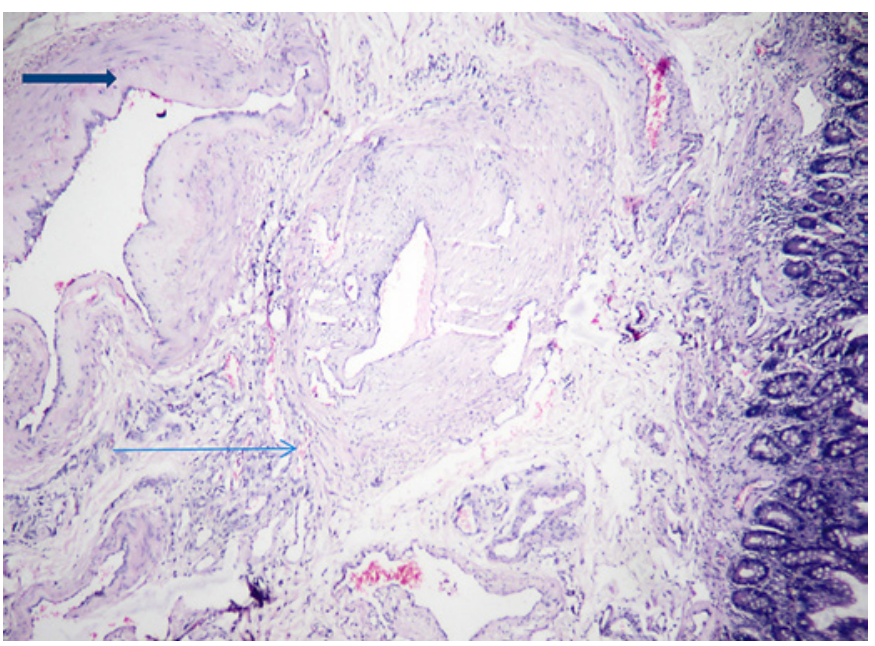

Fig. 3. Photomicrograph shows increase in the submucosal vessels (thin arrow) of varying caliber and arterialized wall (thick arrow) $(\mathrm{H} \& \mathrm{E}, \times 100)$.

\section{Case}

A 12-year-old girl presented with malaise and passage of frank blood in stools for a week. Her mother denied a history of fever, vomiting, and abdominal pain. Episodes of painless bright red blood per rectum were reported. On examination, she was alert, active but sick looking, and markedly pale. Abdomen examination was unremarkable, including inspection of the anus and rectal examination for fissures, polyps, and prolapse. Investigations revealed a hemoglobin level of $6 \mathrm{~g} / \mathrm{dL}$; other baseline tests were with-

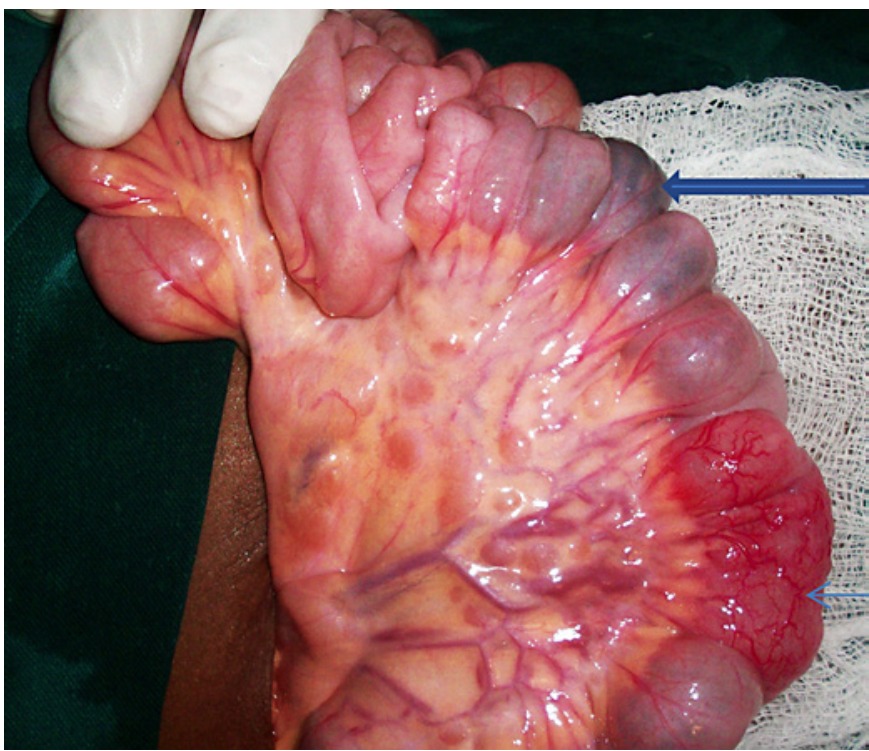

Fig. 2. Intraoperative image of the ileal loop with "angry red" appearance (thin arrow) and blood within the lumen (thick arrow).

in normal limits. Stool culture was negative for pathogens such as enteropathogenic Escherichia coli, Salmonella, and Shigella.

Meckel's scan was negative. Contrast-enhanced computed tomography (CT) of the abdomen showed a contrast-enhanced small bowel segment with leash of vessels in the mesentery (Fig. 1). A provisional diagnosis of bowel AVM was made. After adequate resuscitation with packed red blood cell transfusion and following informed consent, the child was scheduled for surgery. At laparotomy, about $6 \mathrm{~cm}$ length of the Ileum, $12 \mathrm{~cm}$ from the ileocecal junction, was thickened with an "angry-red" appearance due to vessels on the serosa and prominent vessels draining the bowel segment into the mesentery (Fig. 2). Resection and anastomosis of the ileal segment was performed with an uneventful postoperative recovery. At the 6-month followup, she was doing well.

The presence of prominent and multiple vessels in the submucosa, with arteriolization of the vessel wall, led to the diagnosis of AVM of the ileum on histopathology (Fig. 3).

\section{Discussion}

Common causes of LGIB in a child include local conditions such as fissures, polyps, colitis, and Meckel's diverticulum. Occasionally, unusual lesions such as GI duplication, AVM, and ectopic gastric mucosa can be a source for rectal bleeding. For the parents, such symptoms can be a source of considerable anxiety, especially when the bleeding is painless. On the other hand, when the clinical examination and investigations in a given child do not determine the potential cause of bleeding, the 
physician is under pressure to reach a diagnosis and to control the bouts of bleeding. Difficulty in diagnosis is registered when all imaging modalities fail to identify the malformation, leaving the physician in a desperate situation. This scenario is common in children with obscure LGIB (OGIB) due to bowel AVM [1, 2].

In cases of OGIB, capsule endoscopy can help to identify the source of bleeding in about $45-66 \%$ of patients [3]. A combination of single balloon enteroscopy with capsule endoscopy is expected to achieve improved diagnostic utility, although both techniques are simultaneously available in few selected centers [4].

Endoscopic interventions such as injection sclerotherapy, laser, and clips, for example, have a limited role in controlling OGIB [5]. Tagged RBC scan and selective angiography are other options to locate the source of bleeding [5]. Bowel AVM requires a high index of suspicion for diagnosis, as it is known to be associated with OGIB. In the event of all possible investigations not being able to locate the site and cause of bleeding, the next step would be to resort to an intraoperative enteroscopy combined with laparoscopy or laparotomy. Indocyanine green can help to locate a bowel lesion intraoperatively which was not identified by imaging [6].

Adult bowel AVM differs from that of a child. The colon is the common location in the adult, and often there is an association with cardiac disease and aortic stenosis. Syndromic lesions such as the Osler-Weber-Rendu syndrome, Klippel-Trénaunay syndrome, and blue rubber bleb nevus syndrome have a guarded prognosis as they are known to recur and run a protracted course [7]. Also, diffuse involvement of bowel precludes curative surgical excision. Nd YAG laser has limited application in cases where the mucosal vascular lesions are not amenable for surgical excision [8].

\section{Conclusion}

Although rare, painless bleeding per rectum with anemia in a child requires consideration of a surgical cause such as bowel AVM as a possible diagnosis. Contrast-enhanced CT can help identifying these uncommon lesions. Isolated bowel lesions are amenable for surgery and have an excellent prognosis.

\section{Acknowledgment}

The authors wish to acknowledge the clinical support from the Department of Pediatrics.

\section{Statement of Ethics}

Parents have given written informed consent to publish their child's case, including the publication of images.

\section{Conflict of Interest Statement}

The authors have no conflicts of interest to declare

Funding Sources

Not applicable.

\section{Author Contributions}

K.G.: clinical management and manuscript preparation; R.A.: imaging evaluation and clinical correlation; S.J.: histopathology review and photomicrographs.

\section{References}

1 Teach SJ, Fleisher GR. Rectal bleeding in the pediatric emergency department. Ann Emerg Med. 1994 Jun;23(6):1252-8.

2 Mushtaq F, Tudor G, El-Hadi S. Rectal bleeding in children causes and investigations. Paediatr Child Health. 2014;24(11):491-500.

3 Carey EJ, Fleischer DE. Investigation of the small bowel in gastrointestinal bleeding-enteroscopy and capsule endoscopy. Gastroenterol Clin North Am. 2005 Dec;34(4):719-34.
4 Sahn B, Bitton S. Lower gastrointestinal bleeding in children. Gastrointest Endosc Clin N Am. 2016 Jan;26(1):75-98.

5 Soetikno R, Ishii N, Kolb JM, Hammad H, Kaltenbach T. The role of endoscopic hemostasis therapy in acute lower gastrointestinal hemorrhage. Gastrointest Endosc Clin N Am. 2018 Jul;28(3):391-408.

6 Frémond B, Yazbeck S, Dubois J, Brochu P, Garel L, Ouimet A. Intestinal vascular anomalies in children. J Pediatr Surg. 1997 Jun; 32(6):873-7.
7 Meyer CT, Troncale FJ, Galloway S, Sheahan DG. Arteriovenous malformations of the bowel: an analysis of 22 cases and a review of the literature. Medicine (Baltimore). 1981 Jan;60(1):36-48.

8 Pai AK, Fox VL. Gastrointestinal bleeding and management. Pediatr Clin North Am. 2017 Jun;64(3):543-61. 